\title{
Letter to Editor
}

\section{Coil Migration into Common Bile Duct after Postcholecystectomy Hepatic Artery Pseudo-aneurysm Coiling}

\author{
Mukesh Nasa, Zubin Dev Sharma, Gaurav Patil, Rajesh Puri
}

Institute of Digestive and Hepatobiliary Sciences, Medanta-The Medicity, Gurgaon, India

\begin{abstract}
E We report an interesting case of 50-year-old female who had postcholecystectomy hepatic artery pseudoaneurysm. This pseudo-aneurysm was coiled by interventional radiologist. Patient later presented with obstructive jaundice which was due to migration of pseudoaneurysm coils into bile-duct.
\end{abstract}

KEYWORDS: Coil migration, hepatic artery pseudo-aneurysm, jaundice

\section{INTRODUCTION}

Laparoscopic cholecystectomy allows early mobilization and discharge compared to open cholecystectomy but there is ten fold incresead risk of biliary complications with laparoscopic approach. There is risk of vascular injury with this approach in $0.25-0.50 \%$ of procedures. Hepatic artery pseudoaneurysm is a rare post-cholecystectomy complication. Majority of these pseudo-aneurysms are successfully managed by coiling by interventional radiologists.

Spontaneous extrusion of hepatic artery pseudoaneurysm coils into common bile duct is one of the rare possible event that may present as pain abdomen and jaundice.

\section{CASE Report}

A 50-year-old female patient underwent laparoscopic cholecystectomy for symptomatic gall-stone disease. Postoperatively, after about 1 month she had melena with drop in hemoglobin to $4.6 \mathrm{~g} / \mathrm{dL}$. Upper gastrointestinal (GI) endoscopy showed hemobilia. Computed tomography angiography showed hepatic artery pseudoaneurysm [Figures 1 and 2]. She underwent coiling of the pseudoaneurysm by interventional radiologist with the asymptomatic postprocedure course. One year later, she had increasing jaundice with pruritus. Laboratory investigations revealed direct hyperbilirubinemia with raised alkaline phosphatase and gamma-glutamyl transpeptidase. Magnetic resonance cholangiopancreatography revealed stricture of the common hepatic duct at the level of

\begin{tabular}{|l|l|}
\hline \multicolumn{2}{c|}{ Access this article online } \\
\hline Quick Response Code: & Website: www.jdeonline.in \\
\hline
\end{tabular}

cystic duct with coils in situ within hepatic artery pseudoaneurysm. She underwent endoscopic retrograde cholangiopancreatography (ERCP) with the placement of single 10 Fr plastic biliary stent. Brushing from the bile duct and bile cytology were negative for malignancy. She underwent elective ERCP with re-stenting 3 months later, with the placement of two 10 Fr biliary stents. Her clinical course was unremarkable, and she was taken for stent exchange 4 months later. Previously, placed stents were removed. Cholangiogram showed filling defects in the common bile duct. Bile duct was swept with small biliary stone extraction balloon. Metal coils were seen coming out of papilla [Figure 3].

\section{Discussion}

Conventional angiography with embolization of pseudoaneurysm is less invasive than surgery and has been reported to have a success rate between $79 \%$ and $100 \%{ }^{[1]}$ Endovascular intervention has limitations of difficult access and may be complicated by rupture of the pseudoaneurysm sac, incomplete occlusion and perforation of the artery with the vascular catheter. Marone et al. in a single-center study comparing open repair of pseudoaneurysm with endovascular therapy reported open repair as gold standard, especially for an aneurysm involving visceral hilum..$^{[2]}$

Address for correspondence: Dr. Mukesh Nasa, Institute of Digestive and Hepatobiliary Sciences, Medanta-The Medicity, Gurgaon, Haryana, India. E-mail:mukeshnasa78@gmail.com

This is an open access journal, and articles are distributed under the terms of the Creative Commons Attribution-NonCommercial-ShareAlike 4.0 License, which allows others to remix, tweak, and build upon the work non-commercially, as long as appropriate credit is given and the new creations are licensed under the identical terms.

For reprints contact: reprints@medknow.com

How to cite this article: Nasa M, Sharma ZD, Patil G, Puri R. Coil migration into common bile duct after postcholecystectomy hepatic artery pseudo-aneurysm coiling. J Dig Endosc 2018;9:205-7. 


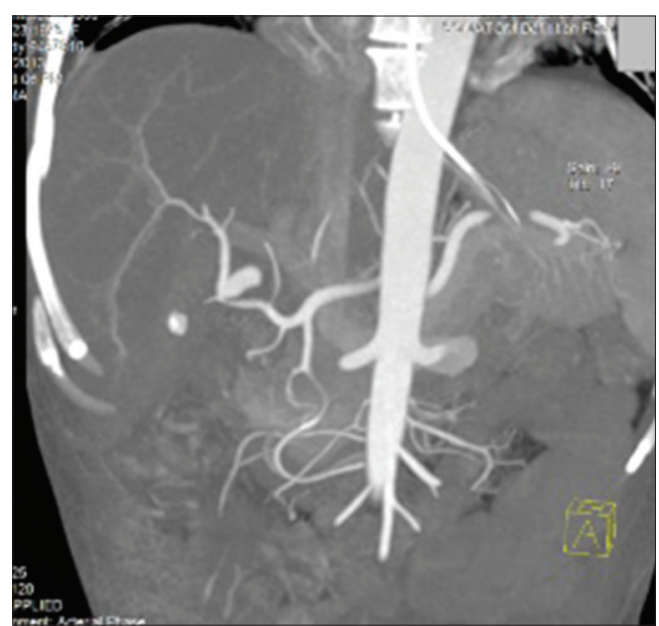

Figure 1: Computed tomography angiogram showing hepatic artery pseudoaneurysm

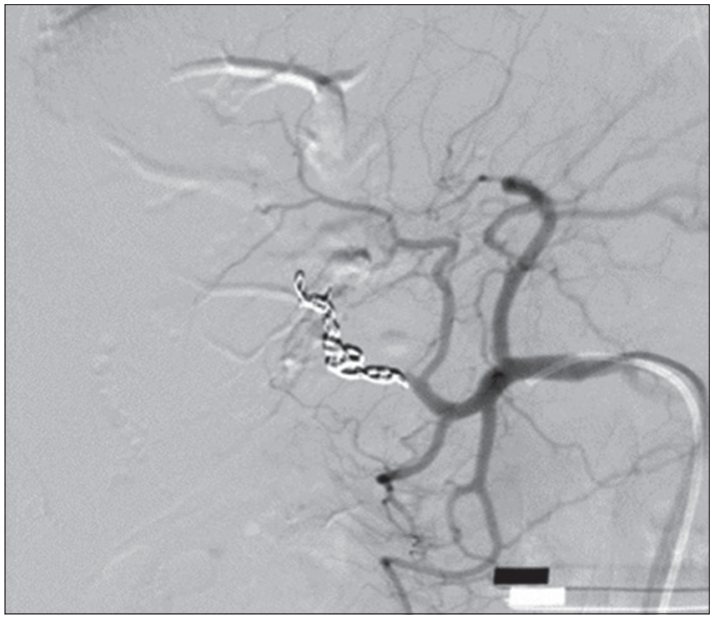

Figure 2: Image showing coil embolization of hepatic artery pseudoaneurysm

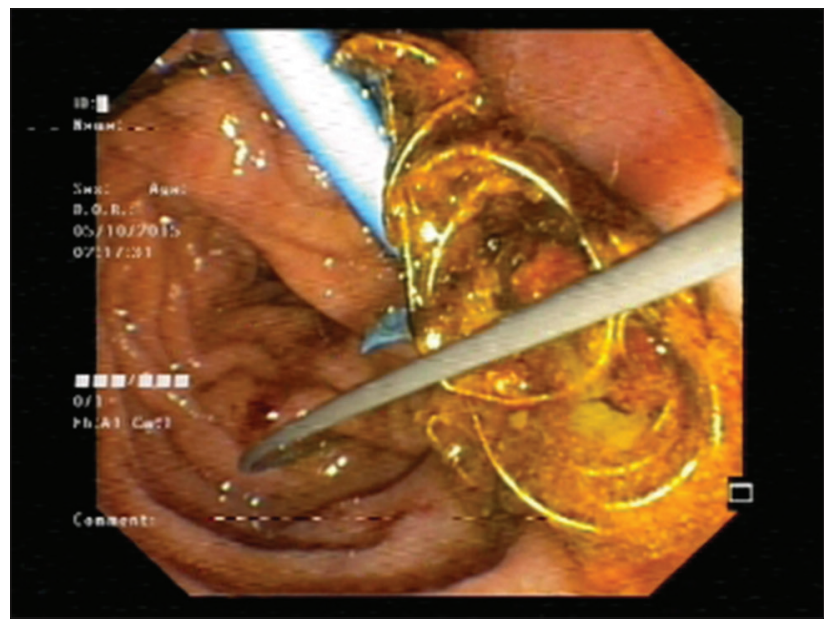

Figure 3: Endoscopic image showing coil coming out of ampulla during endoscopic retrograde cholangiopancreatography

Several endovascular interventions that have been used for the obliteration of visceral artery pseudoaneurysm include coiling, thrombin injection, gel foam, cyanoacrylate glue, and stent-graft placement. Ethylene vinyl alcohol copolymer and multi-layered flow modulator stents have also been used for pseudoaneurysm occlusion. Sometimes, the combination of these techniques is used. ${ }^{[3-5]}$ Endovascular stenting is preferred when the pseudoaneurysm involves large caliber and less tortuous artery. Fully covered stents have the advantage of keeping distal flow patent.

Coils for the obliteration of the pseudoaneurysms and for control of GI bleed has been used extensively for many years. Endoscopic ultrasound allows proper visualization and deployment of the coils in the targeted area. Sharma et al. reported successful obliteration of hepatic artery pseudoaneurysm by endoscopic ultrasound coiling. ${ }^{[6]}$ Philips and Augustine reported another interesting case of endoscopic ultrasound-guided coiling of rectal varices. ${ }^{[7]}$

In our case, endovascular coiling was done by an interventional radiologist. Migration of hepatic artery pseudoaneurysm coils into the bile duct is a rare known complication. Kao et al. reported spontaneous extrusion of hepatic artery pseudoaneurysm coils into the bile duct. ${ }^{[8]}$ A similar case of "coilodocholithiasis" was reported by Bent et al..$^{[9]} \mathrm{A}$ case of splenic artery pseudoaneurysm that underwent coiling and presented 3 months later with pain abdomen and on endoscopy, there was a large gastric ulcer with coil extrusion into the gastric lumen. Inflammation and infection at the coil site have been proposed as an inciting event in the process of coil extrusion. ${ }^{[10]}$

\section{Conclusion}

This case represents a rare known complication of hepatic artery pseudoaneurysm coiling. One must remain vigilant, especially when patient presents with pain abdomen or jaundice during the post-procedure follow-up.

\section{Declaration of patient consent}

The authors certify that they have obtained all appropriate patient consent forms. In the form the patient(s) has/have given his/her/their consent for his/ her/their images and other clinical information to be reported in the journal. The patients understand that their names and initials will not be published and due efforts will be made to conceal their identity, but anonymity cannot be guaranteed.

\section{Financial support and sponsorship}

Nil.

\section{Conflicts of interest}

There are no conflicts of interest. 


\section{REFERENCES}

1. Beattie GC, Hardman JG, Redhead D, Siriwardena AK. Evidence for a central role for selective mesenteric angiography in the management of the major vascular complications of pancreatitis. Am J Surg 2003;185:96-102.

2. Marone EM, Mascia D, Kahlberg A, Brioschi C, Tshomba Y, Chiesa R. Is open repair still the gold standard in visceral artery aneurysm management? Ann Vasc Surg 2011;25:936-46.

3. Szopiński P, Ciostek P, Pleban E, Iwanowski J, Serafin-Król M, Marianowska A, et al. Percutaneous thrombin injection to complete SMA pseudoaneurysm exclusion after failing of endograft placement. Cardiovasc Intervent Radiol 2005;28:509-14.

4. Brox Jiménez A, Parra Membrives P, Díaz Gómez D, González Herráez J, Haurie Girelli J, Escalada Berta J, et al. Transcatheter embolization of a pancreatic pseudoaneurysm using a new liquid embolic agent, ethylene vinyl alcohol copolymer (onyx). Pancreas 2009;38:110-2.

5. Balderi A, Antonietti A, Pedrazzini F, Ferro L, Leotta L,
Peano E, et al. Treatment of a hepatic artery aneurysm by endovascular exclusion using the multilayer cardiatis stent. Cardiovasc Intervent Radiol 2010;33:1282-6.

6. Sharma M, Jindal S, Somani P, Basnet BK, Bansal R. EUS-guided coiling of hepatic artery pseudoaneurysm in 2 stages. VideoGIE 2017;2:262-3.

7. Philips CA, Augustine P. Endoscopic ultrasound-guided management of bleeding rectal varices. ACG Case Rep J 2017;4:e101.

8. Kao WY, Chiou YY, Chen TS. Coil migration into the common bile duct after embolization of a hepatic artery pseudoaneurysm. Endoscopy 2011;43 Suppl 2 UCTN:E364-5.

9. Bent CK, Wright L, Dong PR. "Coildocholithiasis"-common bile duct obstruction secondary to migration of right hepatic artery pseudoaneurysm coils. J Vasc Interv Radiol 2016;27:1741-3.

10. Tekola BD, Arner DM, Behm BW. Coil migration after transarterial coil embolization of a splenic artery pseudoaneurysm. Case Rep Gastroenterol 2013;7:487-91. 